\title{
Benign and severe early-life seizures: a round in the first year of life
}

\author{
Piero Pavone ${ }^{1 *} \mathbb{D}$, Giovanni Corsello ${ }^{2}$, Martino Ruggieri ${ }^{1}$, Silvia Marino ${ }^{3}$, Simona Marino $^{3}$ and Raffaele Falsaperla ${ }^{3}$
}

\begin{abstract}
Background: At the onset, differentiation between abnormal non-epileptic movements, and epileptic seizures presenting in early life is difficult as is clinical diagnosis and prognostic evaluation of the various seizure disorders presenting at this age. Seizures starting in the first year of life including the neonatal period might have a favorable course, such as in infants presenting with benign familial neonatal epilepsy, febrile seizures simplex or acute symptomatic seizures. However, in some cases, the onset of seizures at birth or in the first months of life have a dramatic evolution with severe cerebral impairment. Seizure disorders starting in early life include the "epileptic encephalopathies", a group of conditions characterized by drug resistant seizures, delayed developmental skills, and intellective disability. This group of disorders includes early infantile epileptic encephalopathy also known as Ohtahara syndrome, early myoclonic encephalopathy, epilepsy of infancy with migrating focal seizures, infantile spasms syndrome (also known as West syndrome), severe myoclonic epilepsy in infancy (also known as Dravet syndrome) and, myoclonic encephalopathies in non-progressive disorder.

Here we report on seizures manifesting in the first year of life including the neonatal period. Conditions with a benign course, and those with severe evolution are presented. At this early age, clinical identification of seizures, distinction of each of these disorders, type of treatment and prognosis is particularly challenging. The aim of this report is to present the clinical manifestations of each of these disorders and provide an updated review of the conditions associated with seizures in the first year of life.
\end{abstract}

Keywords: Infantile epilepsy, Epileptic encephalopathies, Early onset seizures, Seizures

\section{Background}

Seizures are not uncommon clinical manifestations in childhood and a frequent reason for consultation in child neurology. In infancy, movements during epileptic seizures are often subtle, unnoticed by parents and, not easily recognized. Seizures are caused by abnormal and excessive discharges of neurons, usually self-limited, and often accompanied by abnormal behavior, and sensorymotor manifestations [1]. The term epilepsy defines the recurrences of two or more unprovoked seizures [2]. Seizure types have been recently classified according to their site of onset in focal, generalized and unknown. The focal seizures are further distinguished in: aware or with impaired awareness, with motor or non-motor onset, and focal to bilateral tonic-clonic; the generalized, in

\footnotetext{
* Correspondence: ppavone@unict.it

${ }^{1}$ Department of Clinical and Experimental Medicine, Section of Pediatrics and Child Neuropsychiatry, A.U.O. Vittorio Emanuele-Policlinico of Catania, Via Santa Sofia 78, 95100 Catania, Italy

Full list of author information is available at the end of the article
}

motor tonic-clonic, other motor and non-motor (Absence); the unknown in motor tonic-clonic, other motor and non-motor, and unclassified. [3, 4]. Various etiological events cause seizures in childhood, the most common being fever, infections, head injury, metabolic dysregulation, noxious perinatal events (e.g., stroke), and hypoxic-ischemic-encephalopathies [5]. Less frequent causes of seizures in childhood include chromosomal deletions, and duplications, cerebral malformations by selected single gene mutations and inborn errors of metabolism [2]. The prenatal and early life periods are critical for brain development with rapid involving synaptogenesis, dendritic arborization, myelination, apoptosis, and priming of excess process, and synapses, all factors which concur for the normal cerebral growth [6]. Any pathologic events during this early period of life might result in severe cerebral impairment with developmental delay and intellectual disability, often associated with epileptic seizures and various comorbidities $[7,8]$. 
Seizures occurring in the first year of life might have an evolution ranging from benign to severe $[9,10]$. Typically benign cases of seizures occurring in the first year of life include Benign Familial Neonatal Epilepsy (BFNE), Febrile Seizures simplex (FSs) and Acute Symptomatic Seizures (ASS). Febrile Seizure complex (FSc) might have a variable prognosis not always predictable. Severe seizures presenting at an early age include the epileptic encephalopathies a group of disorders defined on the basis of "the notion that epileptic activity may contribute to severe neurocognitive and behavioral dysfunction above and beyond what would be expected from the underlying pathology alone". These impairments may have a progressive course over time [11, 12]. Clinical identification of the seizures by the parents and caregivers is challenging, as are diagnosis and prognostic counseling by the pediatricians and specialists in this field. This report aims to present the clinical manifestation of each of these disorders and provide an updated review of the conditions associated with seizures in the first year of life.

\section{Early life seizure with usually benign course Benign familial neonatal epilepsy}

Unlike most cases of neonatal seizures, which have a high frequency of disability, the neonatal prognosis is usually benign in families affected by Benign Familial Neonatal Epilepsy (BFNE) [10, 13]. The clinical features of this disorder are relatively typical: the seizures begin in the first days of life in otherwise healthy looking babies and are typically associated with a family history of neonatal seizures. The affected infants tend to have a normal course in the developmental stages and the seizures tend to gradually disappear within the first months of life. [13-15]. The condition is inherited as an autosomal dominant trait with both genders being affected, and has been associated with a mutation in the KCN gene, localized on chromosome 20q13.33 [16]. With the term "KCNQ2 related epilepsy" are designed clinical conditions encompassing the classical type of BFNE, the Benign Familial Neonatal Infantile Seizures (BFNIS) and the Benign Familial Infantile Seizures (BFIS) [17, 18]. KCNQ2 related disorders are also reported in patients with epileptic encephalopathies [19]. Recently, disorders caused by BFNE have also been reported in individuals with KCNQ3 gene mutations [20]. A large family has been followed for three generations by some of the authors of the present article. In this family, not all of the members showed the classic evolution of the disorder: in one the seizures started at the age of 3 months, another member showed febrile seizures complex with EEG anomalies, and one suffered from focal seizures lasting until the age of 10 years [21].

\section{Acute symptomatic seizures}

Seizures might be provoked by factors with onset in close temporal relationship with a well-documented brain insult. These events are referred to Acute Symptomatic Seizures (ASS) [22], as Situation-Related-Seizures (SRS) or also named as occasional, or reactive, or provoked seizures. The 1989 classification of the ILAE includes these events in the category of situation-related seizures because they show an identifiable proximate cause and do not typically recur spontaneously [23]. Aside from the febrile seizures and the infections directly involving the central nervous system, the seizures might manifest following trauma, intoxication, or anomalous administration of drugs. Other factors inducing ASS include electrolytic dysregulation, acute hypoglycemia, hypocalcemia, and hyponatremia. The occurrence of the ASS is particularly high in the infantile period since, at this age the brain seems to be more susceptible to such insults. The seizures present most frequently as motor tonic-clonic generalized types. Focal or unilateral types are uncommon. Recently, children with manifestations of transient generalized seizures have been reported in association with wild gastroenteritis [24]. A new pathogenetic pathway, the so-called "gut-brain axis", has been reported as a causative event of seizures. Falsaperla et al. [25] have reported a 10-monthold male infant with seizures secondary to cow's milk protein allergy. Neurologic signs disappeared after the suspension of the cow's milk protein.

\section{Febrile seizures simplex}

Febrile Seizures (FS) are the most common convulsive manifestations in childhood, affecting $4-6 \%$ of the pediatric population [26]. FS are classified as simplex or complex [27].

FSs are defined as a short $(<15 \mathrm{~min}$.) generalized seizures, not recurring within $24 \mathrm{~h}$ which occur during a febrile illness not resulting from an acute disease of the nervous system, in a child aged between 6 months and 5 years, with no neurologic deficits and no previous afebrile seizures [27, 28]. Differential diagnosis is made with viral meningitis in the presence of positive neurologic signs, persisting loss of consciousness, and post-ictal drowsiness. In one/third of cases and until the age of 5 years, the seizures tend to reappear with other episodes of fevers. The evolution in epileptic seizures is rare, and almost similar to that of the general population, and no persistent residual signs of motor, behavioral, and cognitive disturbances are reported. In FSs, EEG recordings and brain MRI are not necessary, while the lumbar puncture is advised to be performed in FSs children less than 1-yearold and those under antibiotic treatment. Intravenous, intramuscular, buccal, intranasal or rectal benzodiazepines are administered to stop the crises [28-30]. Prophylactic pharmacologic treatment is not advised [28]. 


\section{Early life seizure with prognosis not predictable Febrile seizures complex}

Children with Febrile Seizures complex (FSc) have characteristic clinical features opposite to those reported in FSs. The principal features of the manifestations are focal, or generalized, and prolonged seizures lasting more than 15 min, recurrence can happen within $24 \mathrm{~h}$ in the course of the same febrile episode, the temperature might not be elevated. Moreover the crises might be associated with post-ictal neurologic abnormalities, most frequently postictal palsy, or manifest in subjects with previous neurologic deficits [28, 29]. FSc might manifest in different ways, with onset before the first year of life or after 5 years, it might be present in alternation with afebrile seizures, or in members of a family affected by Genetic Epilepsy with Febrile Seizures plus (GEFS+). Febrile status epilepticus might also be recorded [27-29]. Patients with brain damage are more affected than those without. Differential diagnosis is posed with cerebral abscesses, meningoencephalitis, cerebral vascular malformations, cortical thrombophlebitis, and autoimmune encephalitis. Diagnostic investigations should include routinary analysis, an EEG recording, lumbar puncture, and plasma electrolytes. Brain MRI might also be indicated in patients with focal seizures, and those with episodes that happened after 5 years of age. Brain MRI is advised in an emergency in patients who present focal post-ictal deficit and persisting loss of consciousness, and also in patients with immunodeficiency, or with seizures of particular long durations. The acute treatment is based on the use of benzodiazepines [30]. In FSc, prophylactic treatment might be useful in reducing the frequency and the duration of the crises but is not considered able to prevent the onset of subsequent epileptic seizures [29]. Very prolonged FSc is thought to be associated with mesial temporal sclerosis and temporal lobe epilepsy, but the direct relationship among these disorders and FSc remains uncertain [31, 32]. FSc might affect child members of a family affected by (GEFS+), a complex autosomal dominant disorder in which individuals present with genetic mutations of SCN2A (a voltage-gated sodium channel), or less frequently of SCN1B [33, 34]. With this mutation, individuals suffering from FSc might belong to a family in whom other members are affected by a variety of seizure types, such as myoclonic, tonic, and tonic-clonic seizures. One/third of the GEFS + patients are reported to have febrile seizures, which manifest with crises of prolonged durations, presenting in children less than 2 years old and, with residual signs including post-ictal hemiplegia [33].

\section{Early life seizures with usually severe course Neonatal seizures}

Neonatal seizures have a fairly high incidence, usually more than in any other period of life. In most cases the neonatal seizures are due to acute dysfunction of the cerebral nervous system and the most common cause is hypoxic-ischemic encephalopathies [35], followed by intracranial hemorrhage, infections and strokes. The incidence rate of neonatal seizures is $1-2 \%$ of life births $[36,37]$. Neonatal seizures are distinguished according to the presentation as clinical seizures, electroclinical seizures and electroencephalographic seizures and based on the pathophysiology in epileptic and non-epileptic seizures [14]. EEG is particularly useful for diagnostic evaluation (Fig. 1).

Neonatal epilepsy syndromes are uncommon, and represent a sizable subgroup of neonatal seizure etiologies [38]. In this subgroup a genetic, metabolic, or structural cause might be identified, whereas in some cases the etiologic event cannot be determined using the current diagnostic investigation. The genetic causes of neonatal epilepsy are distinguished in: malformations of cortical development; genetic-metabolic; genetic vascular; genetic syndromic and genetic-cellular [38]. Neonatal seizures are also included in the cohort of neurodegenerative disorders, and in association with malformative cerebral syndromes. A study on a prospective cohort of newborns with seizures was conducted by Shellhaas et al. [39] on 611 patients enrolled in the Neonatal Seizure Registry US. The study includes neonates with seizures related to epileptic encephalopathies (without structural brain abnormalities), brain malformations, and benign familial epilepsies. Among the group enrolled, 79 (13\%) had epilepsy, (35 epileptic encephalopathy, 32 congenital brain malformation, 11 benign familial neonatal epilepsy and 1 benign neonatal seizures). In this study, $\mathrm{KCN} 2$ variants were the most common genetic anomaly reported within the group of patients with epileptic encephalopathies.

The neonatal seizures may recognized an Inborn Error of Metabolism (IEM), as a putative cause. Among these the Pyridoxine-dependent epilepsy, the pyridox (am)ine 5 '-phosphate oxidase (PNPO) deficiency, GLUT-1 (glucose transporter 1) deficiency, non-ketotic hyperglycinemia, maple syrup urine disease are the most quoted examples [40]. Pyridoxine-dependent epilepsy (PDE) is an autosomal recessive enzyme defect in the vitamin B6 metabolism. In this disorder biochemical and genetic studies are available for a correct diagnosis including elevated urinary alphaaminoadipic semialdehyde excretion and ALDH gene mutation. Treatment consists of the use of pyridoxine, which has been also proposed as an initial diagnostic approach in cases of infantile refractory epilepsy of unknown cause [41]. Pyridox (am)ine 5'-phospate oxidase (PNPO) deficiency is due to the enzyme defect which converts pyridoxine 5 '-phosphate and pyridoxamine 5 '- phosphate (PLP) into pyridoxal $5^{\prime}$-phosphate (PLP). Treatment with pyridox $-5^{\prime}$ phosphate in the first days of life has shown 


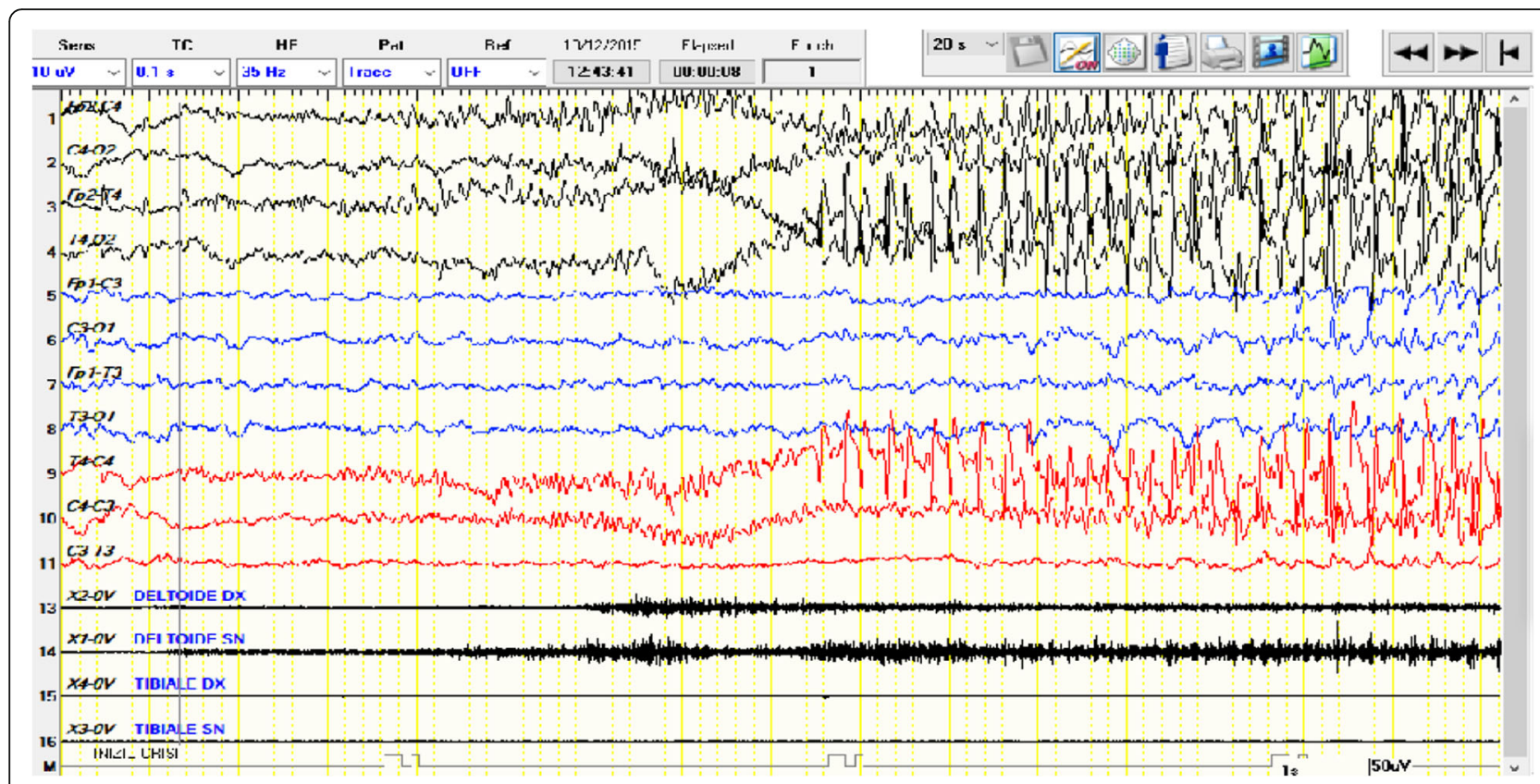

Fig. 1 Four day old boy affected by stroke with neonatal seizures onset. The picture shows the focal discharges located on the right hemisphere

good therapeutic response [42, 43]. GLUT 1 (glucose transporter 1) deficiency presents with respiratory distress, hypotonia, absence of neonatal reflexes and less frequently with arthrogryposis or joint laxity. Diagnosis is related to a mildly elevated cerebrospinal fluid (CSF) glycine levels, and normal or slightly elevated serum or plasma glycine levels. Survey of variants in SLC6A gene might be diagnostic [44]. Non ketotic hyperglycinemia (NKH) is caused by a deficiency in the glycine cleavage system presenting with severe hypotonia and crisis of apnea [45]. The diagnosis is based on the elevated glycine concentrations in CSF, in association with an increased CSF/plasma glycine ratio [46]. Maple syrup urine disease (MSUD) is caused by deficit of branched-chain alfa ketoacid dehydrogenase complex. $\mathrm{Mu}-$ tations in the BGKDHA, BCKDHB, and DBTI genes have been associated with this disorder [47].

Except for PDE, PLP and PNPO no treatment is known for the above mentioned IEM conditions.

Regardless of the etiology of the neonatal seizures, prognosis in most of the cases is severe. In fact the brain is more susceptible in the neonatal period and in infancy than in older children and this vulnerability is linked to a more express activity age-dependent of receptors for excitatory rather than inhibitory neurotransmission [48]. For a long time, neonatal seizures were treated with phenobarbital and phenytoin as the first-line drugs. Recently, phenobarbital and phenytoin treatment in neonatal seizures has been questioned because of doubtful seizure control and for the consequence of long term alterations in brain structures $[49,50]$. As demonstrated in rat CAT neurons, treatment with phenobarbital disrupts GABergic synaptic maturation [51]. Pharmacokinetic data for new drugs in treatment of neonatal seizures is limited. Treatment with levetiracetam has been proposed to be effective in a recent study [52].

\section{Epileptic encephalopathies}

Epileptic encephalopathies include severe epileptic disorders that share similar characteristics: onset in early life, persistent electroencephalographic abnormalities, drugresistant seizures of various types, and cognitive involvement. The definition also includes the condition that seizure activity per se, above and beyond the effects of underlying causal factors, interferes with the developmental skills of the affected children [4, 11, 12]. There is agreement that uncontrolled seizures might provoke a negative effect on the cerebral functions in the affected patients. This is confirmed by the observation that children unresponsive to treatment have a progressive decline along the course of the disorder. At the same time, it is well-known that children with West syndrome show a better prognosis when seizures have an early diagnosis and receive a precocious treatment [53, 54]. The same results have been reported in drug-resistant epileptic children submitted to surgical treatment, with the demonstration of progressive improvement of the cognitive function after the intervention $[55,56]$. Certainly, the persistence of the epileptic seizures and unresponsiveness to the treatment is consistent with the worsening of the cognitive decline in the affected children, but the underlying etiologic factors are of notable importance in contributing to the deleterious brain effect. Epileptic 
encephalopathies are predominantly symptomatic and sporadic, and new technologies have identified several genes involved in the etiology of these disorders [57]. The epileptic encephalopathy manifesting in the first months of life include Early Infantile Epileptic Encephalopathy (EIEE) (also known as Ohtahara syndrome), Early Myoclonic Encephalopathy (EME), Epilepsy of Infancy with Migrating Focal Seizures (EIMFS), Infantile Spams Syndrome (ISS) (also known as West syndrome), Severe Myoclonic Epilepsy in infancy or Dravet Syndrome (DS), and Myoclonic Encephalopathies in non-progressive disorder $[5,11,12,53,54]$.

\section{Early infantile epileptic encephalopathy - early myoclonic encephalopathy}

Early Infantile Epileptic Encephalopathy was first reported by Ohtahara et al. in 1976 [58] and subsequently overviewed in 16 patients by Yamatogy and Ohtahara in 2002 [59]. The syndrome is clinically characterized by early onset seizures presenting in 30\% of cases within the first 10 days of life, by tonic spasms as seizure types (either generalized and symmetrical or lateralized), and with less frequency by focal and myoclonic seizures. The intercritical EEG findings show high voltage bursts of slow waves mixed with multifocal spikes, with phases of flat suppression [59-61] (Fig. 2). Mutations in several genes have been implicated, including ARX, STXBP1, KCNQ2, SLC25A22, and CDKL5 [62-65]. Structural cerebral anomalies are often detected by brain MRI, including cerebral asymmetry, hemimegalencephaly, lissencephaly and focal-cortical dysplasia [61, 65, 66]. Hypotonia, severe developmental delay, and respiratory problems are associated with these seizure types. The prognosis is poor, with severe intellective delay, and resistance to drug treatment and to ketogenic diet. Transition to West syndrome is frequently observed.

The diagnostic criteria for Early Myoclonic Encephalopathy include early onset, and myoclonus as the main seizure type with frequent episodes of erratic partial seizures. Massive myoclonus, or tonic spasms have also been reported. The EEG shows a pattern of burstsuppression. Metabolic disorders are often recognized as a causative event of the disorder as well as brain malformations [67]. Mutation in SLC25A22, which encodes the mitochondrial glutamate/ $\mathrm{H}+$ symporter, has been associated with this encephalopathy [68]. Prognosis is poor. EIEE and EME share many common characteristics and the distinction between these epileptic disorders is questionable [69]. Covanis [70] claims that EME, contrarily to EIEE, might manifest with different characteristics: the tonic seizures are less frequent, the focal seizures (when present) tend to appear later, the myoclonic seizures are early onset, erratic, and frequently massives, and the EEG suppression is longer and the paroxysm shorter. The etiology is mainly of metabolic origin and less structural. Also, the transition of EME in West syndrome is not frequently reported.

\section{Epilepsy of infancy with migrating focal seizures}

The Epilepsy of Infancy with Migrating Focal Seizures (EIMFS) is also referred to as Malignant Migrating Partial Seizures in Infancy (MMPSI) [71, 72]. In most of the cases, EIMFS onset is reported in the firsts 6 months of life, with almost continuous migrating polymorphous focal seizures involving part of the body with hemilateralization and electrographic multifocal discharges.

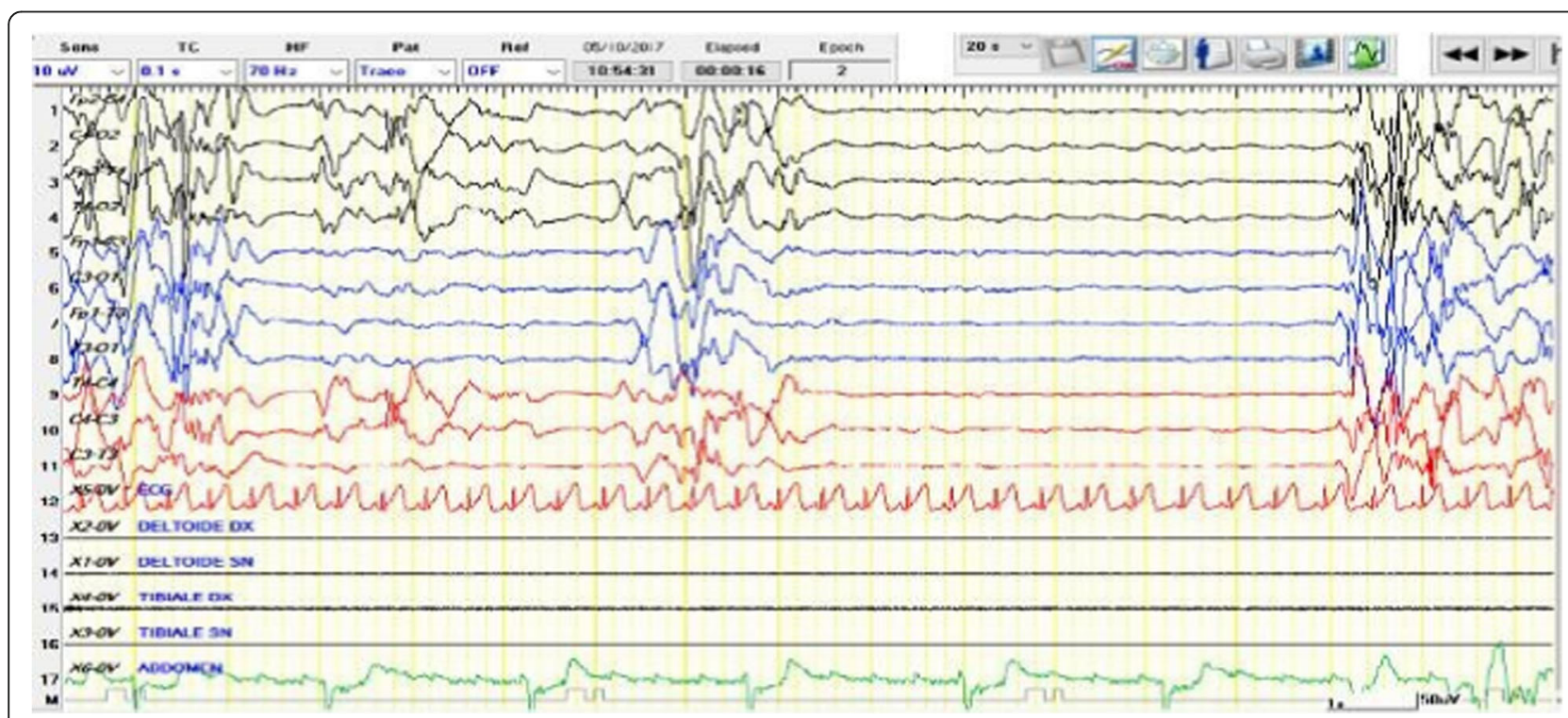

Fig. 2 One month old female with Ohtahara syndrome: The EEG recording shows the typical burst-suppression pattern 
The prognosis is poor, with evolution to the other types of epileptic encephalopathies, such as Ohtahara syndrome and West syndrome. McTague et al. [73] reported the clinical features of 100 children affected by MMPSI. Among these children, focal motor seizures were reported at onset in 64\%; focal seizures affecting alternating sides of the body in 59\%; secondary generalization in $17 \%$; and epileptic spasms in $7 \%$. Moreover, autonomic features were also present in $43 \%$ and generalized tonicclonic seizures in $8 \%$ of the cases. Hypotonia and reduction of the occipitofrontal circumference (OFC) and severe microcephaly was registered in most of the patients. Treatment with a high level of phenytoin gave fairly good results. Among the 14 patients reported by a National surveillance study in association with British Pediatric Neurology Surveillance Unit, at presentation, 10 infants had focal motor seizures mainly involving the face, eyes, and limbs with head-turning; the seizures were generalized in five, generalized tonic in three and clonic in two. An autonomic feature associated with seizures was reported in 12 out 14 cases. EEGs showed various patterns, ranging from subtle burst-suppression with rhythm decrement to hypsarrhythmia, according to the age of infant submitted to the EEG. In this group of patients, genetic analysis identified two patients with mutations in the newly discovered KCNT1 gene [73]. A study was conducted on 12 patients, and data from a further 34 collected from the literature by Howell et al. [74] with the aim of better defining the clinical aspect of early epileptic encephalopathies with SCN2A gene mutations. In the group of 12 patients, multifocal interictal epileptiform discharges were reported in all. At the onset of symptoms, seven patients showed EIMFS clinical expression and two of Ohtahara syndrome. The same authors [74] report in five patients, an improved seizure control with sodium channel blockers using high dosage of phenytoin. The authors [74] concluded that SCN2A encephalopathy is a frequent cause of EIMFS which might manifest with three clinical phenotypes: neonatalinfantile-onset groups (either with severe or intermediate outcomes) and childhood-onset. SCN2A is recognized by these authors as the second most common cause of EIMFS. Pharmacological treatment attempts have been carried out with several, known anticonvulsant drugs including vigabatrin, stiripentol, valproic acid and clobazam, but with poor results [74].

\section{Infantile spasms syndrome}

West syndrome is defined by the classic triad of infantile spasms, hypsarrhythmia, and developmental arrest or regression. West syndrome is also indicated as "infantile spasms" and "epileptic spasms" because the spasms are the most notable event. However, recently this disorder has been indicated with the term "infantile spasms syndrome" (ISS). In fact, this term includes the onset of seizures largely prevailing in infancy, the seizure types, and the EEG findings as present features. As these features tend to occur together, and at the same time the application of the term "syndrome" seems to be correct [3, 75-77]. West syndrome, according to the new nomenclature, is considered a subtype of ISS since not all of the triad is always present at the same time. ISS is the most common among the group of epileptic encephalopathies. The estimated incidence of ISS is 2-3.5 per 10,000 live births [78]. In the typical manifestation, the seizures appear within the first year of life, usually between 4 and 6 months, with episodes of axial spasms of short duration occurring in clusters and at awakening. Psychomotor delay might precede, follow or coincide with the spasms. In rare occasions, the spasms might not manifest clearly and might express with less obvious signs, which are referred to as "subtle spasms". The intercritical EEG presents with a high voltage arrhythmia and asynchronous, slow, and sharp waves, in a chaotic distribution with multifocal spikes and poly-spikes. Critical EEG might show a pattern of synchronous and symmetric spike- wave discharges (Fig. 3). Atypical modified hypsarrhythmia might be observed at the intercritical EEG with a pattern of asymmetric features, focal discharges, and semi-periodic burst- suppression [75]. Prognosis in most of the cases is severe, both for the control of seizures and for intellective delay. The underlying causes of ISS are numerous. Symptomatic causes are the most common, being identified in about $60-70 \%$ of cases. Among these, the most frequent are the outcomes of hypoxic-ischemic encephalopathy and perinatal strokes, neurocutaneous syndromes including Sturge-Weber syndrome, and Tuberous Sclerosis Complex, structural brain disorders, malformative syndromes, inborn errors of metabolism and as recently shown immunologic factors. Gene mutations have been recognized as a causative event of ISS. The first reports of gene mutation in ISS were linked to the Aristeless (ARX1) and the cyclin-depend Kinase-like (CDKL5) [79]. Genes frequently involved with ISS are the PAFAH1B1/LIS1, DCX, and TUBA1A855. Other genes implicated in the etiology of ISS are DKL5, STXBP1, KCNQ2, GRIN2A, MAG12, SPTAN, FOXG1, NSD1, WDR4 and RARS2 [60, 80-83]. There are multiple treatment options for ISS, which can be used together or individually under different situations. Hormonal, pharmacologic, ketogenic diet, and surgery are the eventual options for treatment. Adrenocorticotrophic hormone $(\mathrm{ACTH})$ is widely used, with a wide range of dosage, but the most carried out is $2-3 \mathrm{IU} / \mathrm{Kg} /$ day. ACTH treatment is usually conducted for 3-4 weeks. Pharmacologic treatment is linked to the use of vigabatrin (50-125 mg/kg/day) alone or in association with other drugs. A ketogenic diet (ATKINS) is recommended by several authors, firstly by 


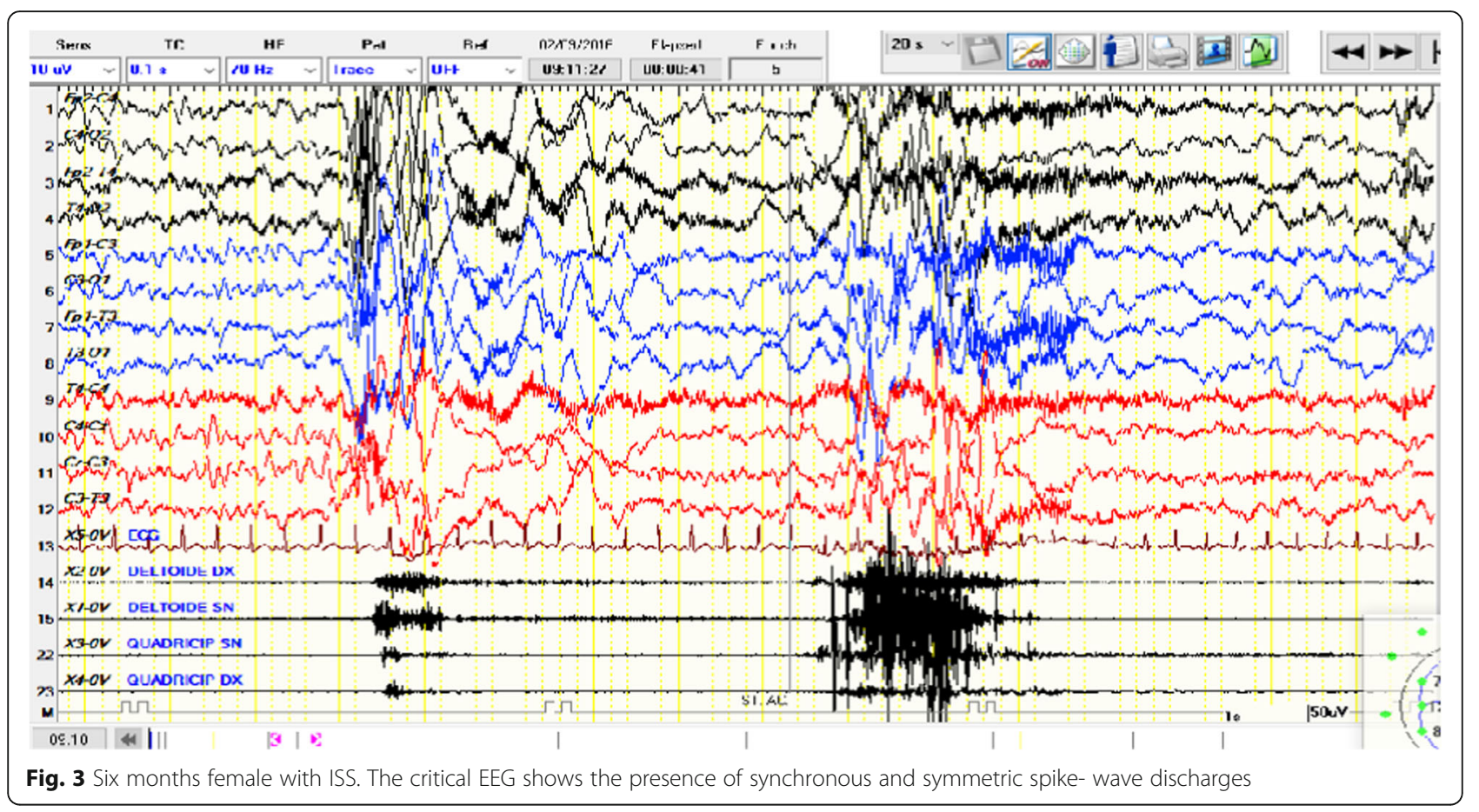

Kossofl, who report good results in more than $45 \%$ of the children treated with this diet [84]. Surgery is rarely used and restricted to cases of documented focal epileptogenesis and when pharmacologic treatment did not help [85].

\section{Severe myoclonic epilepsy in infancy- Dravet syndrome}

Since the initial description in 1978 [86] and subsequent reports of Dravet, the clinical features of this disorder are represented by severe myoclonic epilepsy with onset in infancy (SMEI), associated with multiple seizure types, last-during epileptic seizures with frequent episodes of status epilepticus, often triggered by fever $[87,88]$. The incidence is reported as about 1 in 40,000 infants [89, 90]. In its classical clinical feature, patients affected by this disorder initially growth normally, and seizures begin around the age of 6-8 months trigger by fever, and presenting with either low and high temperature. Seizures are last -during and might have generalized or unilateral expression. Less commonly, seizures might also develop without fever. The EEG might be initially normal or present with diffuse or unilateral slowing after the episodes of prolonged course. There are five principal diagnostic criteria for classical DS: normal developmental before seizure onset; two or more febrile seizures complex before the age of 12 months; myoclonic, hemiclonic or generalized tonic-clonic seizures; two last-during seizures; and refractory seizures after the age of 2-years [88]. However, in patients with SMEI related to SCN1A gene mutations, some of the above-mentioned clinical signs might be absent, including the different age of onset, type of seizures, EEG pattern, and the non-involvement of intellective capacity [91-94]. For DS linked to SCN1A mutation, the term SCN1A-related epilepsy syndrome has been proposed. This syndrome might also show a wide clinical expression involving not only the brain but also cardiac, hearing, vision, movement issues, urinary, bowel, and endocrine functions [95]. Psychiatric disturbances and autistic behavioral have frequently been reported [95]. The EEG typically shows focal or multifocal spike-waves, sharp waves, and slow waves and spikes activity [88]. In approximately $70-80 \%$ of cases, DS is related to a genetic disorder, mostly carrying a de novo SCN1A mutation, and including truncating, missense, and splice- site mutations in $40 \%, 40 \%$, and $20 \%$ of cases, respectively [96]. Other genes have been associated with DS-like phenotypes, including SCN2A, SCN8A, SCN9A, SCN1B, PCDH19, GABRA1, GABRAG2, STXBP1, HCN1, CHD2, and KCNA2 [95-100]. SCN1A mutations cause an inhibition of the GABAergic inhibitory interneurons, leading to excessive neuronal excitation. This model is referred to as the interneuron hypothesis and is the most accepted mechanism for DS [96-98]. The SCN1A genes encode nine mammalian voltage-gated sodium channel alfa subunits, and their mutation is one of the most common causes of epilepsy detected in $70 \%$ to $85 \%$ of patients with DS and $3 \%$ to $6 \%$ of patients with generalized epilepsy with febrile seizures plus (GEFS+) [91, 97-100]. SCN1A haploinsufficiency producing Nav1.1 dysfunction mainly affects GABAergic neurons, which according to the affected site, cortex, cerebellum, basal ganglia, or hypothalamus, are the cause of epileptic seizure, ataxia, crouching gait, thermal dysregulation, and sleep disturbances [96, 98, 101, 102]. 
The prognosis for DS is severe for both epileptic seizures and cognitive impairment, and the mortality rate is significant and half of the deaths are recorded as Sudden Unexpected Death (SUDEP) [103]. DS treatment is based on the use of appropriate drugs. Sodium channel blocking drugs are not advised in cases of DS due to the genetic defects affecting the sodium channels. In most cases, the drugs used in the treatment of DS produce little benefit. Pharmacological treatment attempts have been carried out with oxcarbamazepine, phenytoin, bromides, topiramate, levetiracetam, vigabatrin, stiripentol (STP), valproic acid, clobazam. [73] The effectiveness of STP was tested in 32 patients affected by DS, 15 of which had SCN1A mutations. The authors found that STP treatment was able to reduce the frequency of seizures in $72 \pm 23 \%$ of the mutation group, compared to $50 \pm 40 \%$ of the non-mutation group [104]. Triple treatment with valproate, topiramate, and STP has been effective in DS case report [105]. In a study of Myers et al. [106] performed on 41 patients with DS, treatment with STP displayed a long-term reduction of about $50 \%$ of cases both in patients with generalized than those with focal epileptic seizures. In general STP treatment in DS is effective and well-tolerated and markedly reduce the frequency of prolonged seizures [107]. New drugs have been proposed for the treatment of SD [108].

\section{Myoclonic encephalopathies in nonprogressive disorder}

The syndrome, also termed as "Myoclonic Status in Nonprogressive Encephalopathies (MSNE)" begins in early age, with an average age of 10 months [109, 110].

Three subgroups are recognized with a different presentation concerning the etiology, clinical aspect, EEG, and the evolution. In the first group, the etiology is genetic; the seizures are myoclonic or myoclonic absencetypes. The EEG features consist of periodic theta-delta activity predominant in the central regions or might appear as brief runs of slow delta rhythm in the posterior regions. In the second group, the etiology is unknown with bilateral positive myoclonic jerks or relevant abnormal movements; the EEG shows diffuse slow background with status epilepticus or theta-delta rhythm prevalent in frontal regions. In the third group, the developmental delay is mild, and focal motor seizures involve mainly the face; the EEG displays generalized spike-wave paroxysms [111].

\section{Conclusions}

The diagnosis of early-life seizures is complex, and includes conditions that can have a favorable course or dramatic effects. The onset of the first episode is cause of great concern for the parents and caregivers, and there is pressure for the pediatrician to express an immediate diagnosis. Correct diagnosis can help to produce appropriate treatment and accurate prognosis. The first problem is to differentiate epileptic seizures from abnormal non-epileptic movements. Video-registration from the parents might help with this distinction.

Early onset seizures are a clinical expression of various disorders with different etiologies and prognosis. The benign type of early-life seizures is associated with a normal physical and neurological examination, adequate developmental milestones, good eye contact, and prompt response to the archaic reflexes. In this regard, the absence of cerebral impairment is often a positive prognostic sign.

Epileptic seizures are usually accompanied by others abnormal clinical manifestations. A clinical examination might indicate the presence of anomalies on the skin, face, and body organs, indicating a neurocutaneous, a malformative syndrome, an inborn errors of metabolism or other neurologic disorders.

It is also relevant to note the frequency and complexity of seizure types which might be indicative of the severity of the disorders. Video-EEG registration are of notable importance as are the ophthalmologic examination and brain MRI. Recently, genetic analyses are revealing the gene mutations involved and will likely make relevant contributions to assignments of a correct diagnosis. In the group of epileptic encephalopathies, the electroclinical definition and diagnosis of each of the various disorders particularly in the precocious phases is relevant but not simple, because of the similarity of presentation and characteristic of seizures of the affected infants to shift from one type to another. Moreover, the electroclinical patterns reported in these patients might be influenced by several factors such as the causative event, the age of seizure onset, the time of EEG recording and the treatment already performed leading to inconclusive results on the type of epileptic disorders. All of the seizures belonging to the group of EE show resistance to pharmacological drugs, to hormonal treatments, and to ketogenic diet. Prognosis in EE patients is usually severe and mainly based on the causative event. Correct diagnosis, appropriate and precocious treatment, are the best way to improve the course of the disorders.

\section{Abbreviations \\ BFIS: Benign Familial Infantile Seizures; BFNE: Benign Familial Neonatal Epilepsy; DS: Dravet Syndrome; EIEE: Early Infantile Epileptic Encephalopathy; EIMFS: Epilepsy of Infancy with Migrating Focal Seizures; EME: Early Myoclonic Encephalopathy; FS: Febrile seizures; FSc: Febrile Seizures Complex; FSs: Febrile Seizures Simplex; GEFS+: Genetic Epilepsy with Febrile Seizures plus; ISS: Infantile Spams Syndrome; SRS: Situation-Related-Seizures}

Acknowledgements

We wish to thank American Manuscript Editors for editing the paper.

Availability of data and materials

Please contact authors for data requests. 


\section{Authors' contributions}

All the authors have equally contributed to write the article. All authors read and approved the final manuscript.

\section{Ethics approval and consent to participate}

Ethics approval was obtained by the Local Ethical Committee (University Hospital Policlinico-Vittorio Emanuele, Catania, Italy).

\section{Competing interests}

Giovanni Corsello is the Editor-in-Chief of Italian Journal of Pediatrics, and declares that he has no competing interests in light of this. The remaining authors also declare that they have no competing interests.

\section{Publisher's Note}

Springer Nature remains neutral with regard to jurisdictional claims in published maps and institutional affiliations.

\section{Author details}

'Department of Clinical and Experimental Medicine, Section of Pediatrics and Child Neuropsychiatry, A.U.O. Vittorio Emanuele-Policlinico of Catania, Via Santa Sofia 78, 95100 Catania, Italy. ${ }^{2}$ Department of Maternal and Child Health, University of Palermo, Palermo, Italy. ${ }^{3}$ University-Hospital 'Policlinico-Vittorio Emanuele, University of Catania, Catania, Italy.

\section{Received: 10 March 2018 Accepted: 18 April 2018}

Published online: 15 May 2018

\section{References}

1. Major P, Thiele EA. Seizures in children. Pediatr Rev. 2007;28:363-71.

2. Sidhu R, Velayudam K, Barnes G. Pediatric seizures. Pediatr Rev. 2013:34:333-41.

3. Fisher RS, Cross JH, D'Souza C, French JA, Haut SR, Higurashi N, Hirsch E, Jansen FE, Lagae L, Moshé SL, Peltola J, Roulet Perez E, Scheffer IE, Schulze-Bonhage A, Somerville E, Sperling M, Yacubian EM, Zuberi SM. Instruction manual for the ILAE 2017 operational classification of seizure types. Epilepsia. 2017;58:531-42. https://doi.org/10.1111/epi.13671. Epub 2017 Mar 8. PubMed 50 PMID:28276064.

4. Fisher RS, Cross JH, French JA, Higurashi N, Hirsch E, Jansen FE, Lagae L, Moshé SL, Peltola J, Roulet Perez E, Scheffer IE, Zuberi SM. Operational classification of seizure types by the international league against epilepsy: position paper of the ILAE Commission for Classification and Terminology. Epilepsia. 2017;58:522-30. https://doi.org/10.1111/epi.13670.

5. Berg AT, Langfitt JT, Testa FM, Levy SR, DiMario F, Westerveld M, Kulas J Global cognitive function in children with epilepsy: a community-based study. Epilepsia. 2008;49(4):608-14. Epub 2007 Dec 6

6. Camfield P, Camfield C. Incidence, prevalence and aetiology of seizures and epilepsy in children. Epileptic Disord. 2015;17:117-23.

7. Berg AT, Langfitt JT, Testa FM, Levy SR, DiMario F, Westerveld M, Kulas J. Residual cognitive effects of uncomplicated idiopathic and cryptogenic epilepsy. Epilepsy Behav. 2008;13:614-9.

8. Jensen FE. Epilepsy as a spectrum disorder: implications from novel clinical and basic neuroscience. Epilepsia. 2011:52(Suppl 1):1-6. https://doi.org/10. 1111/j.1528-1167.2010.02904.x

9. Berg AT, Tarquinio D, Koh S. Early life epilepsies are a comorbidity of developmental brain disorders. Semin Pediatric Neurol. 2017:24:251-63.

10. Watanabe K. Seizures in the newborn and young infants. Folia Psychiatr Neurol Jpn. 1981;35:275-80.

11. Capovilla G, Wolf P, Beccaria F, Avanzini G. The history of the concept of epileptic encephalopathy. Epilepsia. 2013:54(Suppl 8):2-5. https://doi.org/10. 1111/epi.12416.

12. Berg AT, Berkovic SF, Brodie MJ, Buchhalter J, Cross JH, van Emde BW, Engel J, French J, Glauser TA, Mathern GW, Moshé SL. Revised terminology and concepts for organization of seizures and epilepsies: report of the ILAE commission on classification and terminology, 2005-2009. Epilepsia. 2010;51:676-85

13. Grinton BE, Heron SE, Pelekanos JT, Zuberi SM, Kivity S, Afawi Z, Williams TC, Casalaz DM, Yendle S, Linder I, Lev D, Lerman-Sagie T, Malone S, Bassan H, Goldberg-Stern H, Stanley T, Hayman M, Calvert S, Korczyn AD, Shevell M, Scheffer IE, Mulley JC, Berkovic SF. Familial neonatal seizures in 36 families: clinical and genetic features correlate with outcome. Epilepsia. 2015;56:1071-80. https://doi.org/10.1111/epi.13020. PubMed PMID: 25982755
14. Kanhere S. Recent advances in neonatal seizures. Indian J Pediatr. 2014;81:917-25

15. Pavone L, Mazzone D, La Rosa M, Li Volti S, Mollica F. Le convulsion familiari benigne. Studio di una famiglia. Pediatria Oggi. 1982;11:375-8.

16. Maljevic S, Vejzovic S, Bernhard MK, Bertsche A, Weise S, Döcker M, Lerche $\mathrm{H}$, Lemke JR, Merkenschlager A, Syrbe S. Novel KCN mutation in a large family with benign familial neonatal epilepsy: a rare cause of neonatal seizures. Mol Syndromol. 2016;7:189-96.

17. Zara F, Specchio N, Striano P, Robbiano A, Gennaro E, Paravidino R, Vanni N. Genetic testing in benign familial epilepsies of the first year of life: clinical and diagnostic significance. Epilepsia. 2013;54:425-36.

18. Allen NM, Mannion M, Conroy J, Lynch SA, Shahwan A, Lynch B, King MD. The variable phenotypes of KCNQ-related epilepsy. Epilepsia. 2014;55:e99-105.

19. Weckhuysen S, Mandelstam S, Suls A, Audenaert D, Deconinck T, Claes LR, Deprez L, Smets K, Hristova D, Yordanova I, Jordanova A, Ceulemans B, Jansen A, Hasaerts D, Roelens F, Lagae L, Yendle S, Stanley T, Heron SE, Mulley JC, Berkovic SF, Scheffer IE, de Jonghe P. KCNQ2 encephalopathy: emerging phenotype of a neonatal epileptic encephalopathy. Ann Neurol. 2012;71(1):15-25. https://doi.org/10.1002/ana.22644 PubMed PMID: 22275249.

20. Singh NA, Westenskow P, Charlier C, Pappas C, Leslie J, Dillon J, Anderson VE, Sanguinetti MC, Leppert MF, BFNC Physician Consortium. KCNQ2 and KCNQ3 potassium channel genes in benign familial neonatal convulsions: expansion of the functional and mutation spectrum. Brain. 2003:126(Pt 12):2726-37.

21. Pavone $P$, Pratico AD, Falsaperla $R$, Striano $P$, Ruggieri M. Is benign familial neonatal epilepsy always familially benign? In press.

22. Beghi E, Carpio A, Forsgren L, Hesdorffer DC, Malmgren K, Sander JW, Tomson T, Hauser WA. Recommendation for a definition of acute symptomatic seizure. Epilepsia. 2010 Apr;51(4):671-5. https://doi.org/10. 1111/j.1528-1167.2009.02285.x.

23. Proposal for revised classification of epilepsies and epileptic syndromes. Commission on classification and terminology of the international league against epilepsy. Epilepsia. 1989;30(4):389-99. PubMed PMID: 2502382

24. Xue CC, Liang YF, Pan GQ, Li CC. Benign infantile convulsions associated with mild gastroenteritis: a clinical analysis and follow-up study. Zhongguo Dang Dai Er Ke Za Zhi. 2017;19:1191-5.

25. Falsaperla R, Romano C, Pavone P, Vitaliti G, Yuan Q, Motamed-Gorji N, Lubrano R. The gut-brain axis: a new pathogenic view of neurologic symptoms - description of a pediatric case. J PediatrNeurosci. 2017:12:105-8.

26. Annegers JF, Hauser WA, Lee JR, Rocca WA. Incidence of acute symptomatic seizures in Rochester, Minnesota, 1935-1984. Epilepsia. 1995:36:327-33.

27. Patterson JL, Carapetian SA, Hageman JR, Kelley KR. Febrile seizures. Pediatr Ann. 2013:42:249-54

28. Capovilla G, Mastrangelo M, Romeo A, Vigevano F. Recommendations for the management of "febrile seizures": ad hoc task force of LICE guidelines commission. Epilepsia. 2009:50(Suppl 1):2-6. https://doi.org/10.1111/ j.1528-1167.2008.01963.x

29. Knudsen FU Febrile seizures: treatment and prognosis. Epilepsia. 2000;41(1):2-9.

30. Vitaliti G, Castagno E, Ricceri F, Urbino A, Di Pianella AV, Lubrano R, Falsaperla R. Epidemiology and diagnostic and therapeutic management of febrile seizures in the Italian pediatric emergency departments: a prospective observational study. Epilepsy Res. 2017;129:79-85.

31. Bast T, Carmant L. Febrile and other occasional seizures. Handb Clin Neurol. 2013;111:477-91. https://doi.org/10.1016/B978-0-444-52891-9.00052-X.

32. Asadi-Pooya AA, Nei M, Rostami C, Sperling MR. Mesial temporal lobe epilepsy with childhood febrile seizure. Acta Neurol Scand. 2017;135(1):88-91. https://doi.org/10.1111/ane.12566

33. Wallace RH, Scheffer IE, Parasivam G, Barnett $\mathrm{S}$, Wallace GB, Sutherland GR, Berkovic SF, Mulley JC. Generalized epilepsy with febrile seizures plus: mutation of the sodium channel subunit SCN1B. Neurology. 2002:58:1426-9.

34. Shi X, Yasumoto S, Kurahashi H, Nakagawa E, Fukasawa T, Uchiya S, Hirose S. Clinical spectrum of SCN2A mutations. Brain and Development. 2012;34:541-5. https://doi.org/10.1016/j.braindev.2011.09.016.

35. Shetty J. Neonatal seizures in hypoxic-ischaemic encephalopathy-risks and benefits of anticonvulsant therapy. Dev Med Child Neurol. 2015;57(Suppl 3):40-3.

36. Cowan LD. The epidemiology of the epilepsies in children. Ment Retard Dev Disabil Res Rev. 2002;8:1711-81. 
37. Hauser WA, Kurland LT. The epidemiology of epilepsy in Rochester, Minnesota,1935 through 1967. Epilepsia. 1975;16:1-66.

38. EJT A, Olson HE. Neonatal epilepsy genetics. In: Semin Fetal Neonatal Med 2018. https://doi.org/10.1016/.jsiny.2018.01.003

39. Shellhaas RA, Wusthoff CJ, Tsuchida TN, et al. Profile of neonatal epilepsies: characteristics of a prospective US cohort. Neurology. 2017;89(9):893-9. https://doi.org/10.1212/WNL.0000000000004284.

40. Sharma S, Prasad AN. Inborn errors of metabolism and epilepsy: current understanding, diagnosis, and treatment approaches. Int J Mol Sci. 2017;18(7) https://doi.org/10.3390/ijms18071384.

41. Oliveira R, Pereira C, Rodrigues F, Alfaite C, Garcia P, Robalo C, Fineza I, Gonçalves O, Struys E, Salomons G, Jakobs C, Diogo L. Pyridoxine-dependent epilepsy due to antiquitin deficiency: achieving a favourable outcome. Epileptic Disord. 2013;15(4):400-6. https://doi.org/10.1684/epd.2013.0610

42. Hatch J, Coman D, Clayton P, Mills P. Normal neurodevelopmental outcomes in PNPO deficiency: a case series and literature review. JIMD Rep. 2016;26:91-7. https://doi.org/10.1007/8904_2015_482.

43. Ware TL, Earl J, Salomons GS, Struys EA, Peters HL, Howell KB, Pitt JJ, Freeman JL. Typical and atypical phenotypes of PNPO deficiency with elevated CSF and plasma pyridoxamine on treatment. Dev Med Child Neurol. 2014;56(5):498-502. https://doi.org/10.1111/dmcn.12346.

44. Zhang L, Zhou D, Guan W, Ren W, Sun W, Shi J, Lin Q, Zhang J, Qiao T, Ye Y, Wu Y, Zhang Y, Zuo X, Connor KL, Xu G. Pyridoxine 5'-phosphate oxidase is a novel therapeutic target and regulated by the TGF- $\beta$ signalling pathway in epithelial ovarian cancer. Cell Death Dis. 2017;8(12):3214. https://doi.org/ 10.1038/s41419-017-0050-3.

45. Kurolap A, Hershkovitz T, Baris HN. GLYT1 encephalopathy. GeneReviews ${ }^{\oplus}$. Seattle: University of Washington, Seattle; 2017. p. 1993-2018.

46. Lin Y, Zheng Z, Sun W, Fu Q. A novel compound heterozygous variant identified in GLDC gene in a Chinese family with non-ketotic hyperglycinemia. BMC Med Genet. 2018;19(1):5. https://doi.org/10.1186/s12881-017-0517-1.

47. Han B, Han B, Guo B, Liu Y, Cao Z. Two novel mutations in the BCKDHB gene that cause maple syrup urine disease. Pediatr Neonatol. 2018; https://doi.org/10.1016/j.pedneo.2018.01.006.

48. Sankar R, Painter MJ. Neonatal seizures: after all these years we still love what doesn't work. Neurology. 2005;64:776-7.

49. Pisani F, Spagnoli C. Acute symptomatic neonatal seizures in preterm neonates: etiologies and treatments. Semin Fetal Neonatal Med. 2017; https://doi.org/10.1016/j.siny.2017.12.003.

50. Dang LT, Silverstein FS. Drug treatment of seizures and epilepsy in newborns and children. Pediatr Clin N Am. 2017;64(6):1291-308 https://doi.org/10.1016/.jpcl.2017.08.007.

51. Al-Muhtasib N, Sepulveda-Rodriguez A, Vicini S, Forcelli PA. Neonatal phenobarbital exposure disrupts GABAergic synaptic maturation in rat CA1 neurons. Epilepsia. 2018; https://doi.org/10.1111/epi.13986.

52. McHugh DC, Lancaster S, Manganas LN. A systematic review of the efficacy of Levetiracetam in neonatal seizures. Neuropediatrics. 2018;49(1):12-7. https://doi.org/10.1055/s-0037-1608653.

53. Howell KB, Harvey AS. Epileptic encephalopathy: use and misuse of a clinically and conceptually important concept. Epilepsia. 2016;57:343-7.

54. Auvin S, Cilio MR, Vezzani A. Current understanding and neurobiology of epileptic encephalopathies. Neurobiol Dis. 2016;92(Pt A):72-89.

55. Vasconcellos E, Wyllie E, Sullivan S, Stanford L, Bulacio J, Kotagal P, Bingaman W. Mental retardation in pediatric candidates for epilepsy surgery: the role of early seizure onset. Epilepsia. 2001;42:268-74.

56. D'Argenzio L, Colonnelli MC, Harrison S, Jacques TS. Cognitive outcome after extratemporal epilepsy surgery in childhood. Epilepsia. 2011;52:1966-72.

57. Nieh SE, Sherr EH. Epileptic encephalopathies: new genes and new pathways. Neurotherapeutics. 2014;11(4):796-806. https://doi.org/10.1007/ s13311-014- 0301-2.

58. Ohtahara S, Ishida T, Oka E, Yamatogi Y, Inoue H, Kanda S. On the specific age dependent epileptic syndrome: the early-infantile epileptic encephalopathy with suppression burst. No to Hattatsu (Tokio). 1976;8:270-80.

59. Yamatogi Y, Ohtahara S. Early-infantile epileptic encephalopathy with suppression-bursts, Ohtahara syndrome; its overview referring to our 16 cases. Brain and Development. 2002;34:13-23.

60. Pavone P, Spalice A, Polizzi A, Parisi P, Ruggieri M. Ohtahara syndrome with emphasis on recent genetic discovery. Brain and Dev. 2012;34:459-68.

61. Ohtsuka Y, Sato M, Sanada S, Yoshinaga H, Oka E. Suppression-burst patterns in intractable epilepsy with focal cortical dysplasia. Brain and Development. 2000;22:135-8.
62. Deprez L, Jansen A, De Jonghe P. Genetics of epilepsy syndromes starting in the first year of life. Neurology. 2009;72:273-81.

63. Kato M, Saitoh S, Kamei A, Shiraishi H, Ueda Y, Akasaka M, Tohyama J, Akasaka N, Hayasaka K. A longer polyalanine expansion mutation in the ARX gene causes early infantile epileptic encephalopathy with suppression-burst pattern (Ohtahara syndrome). Am J Hum Genet. 2007:81:361-6.

64. Saitsu H, Kato M, Mizuguchi T, Hamada K, Osaka H, Tohyama J. De novo mutations in the gene encoding STXBP1 (MUNC18-1) cause early infantile epileptic encephalopathy. Nat Genet. 2008;40:782-8.

65. Kato M, Yamagata T, Kubota M, Arai H, Yamashita S, Nakagawa T. Clinical spectrum of early onset epileptic encephalopathies caused by KCNQ2 mutation. Epilepsia. 2013;54:1282-7.

66. Nakamura K, Kato M, Osaka H, Yamashita S, Nakagawa E, Haginoya K. Clinical spectrum of SCN2A mutations expanding to Ohtahara syndrome. Neurology. 2013;81:992-8.

67. Bastos H, da Silva PF, de Albuquerque MA, Mattos A, Riesgo RS, Ohlweiler L. Proteus syndrome associated with hemimegalencephaly and Ohtahara syndrome: report of two cases. Seizure. 2008;17:378-82.

68. Molinari F, Kaminska A, Fiermonte G, Boddaert N, Raas-Rothschild A. Mutations in the mitochondrial glutamate carrier SLC25A22 in neonatal epileptic encephalopathy with suppression bursts. Clin Genet. 2009;76:188-94

69. Djukic A, Lado FA, Shinnar S, Moshé SL. Are early myoclonic encephalopathy (EME) and the Ohtahara syndrome (EIEE) independent of each other? Epilepsy Res. 2006;70(Suppl 1):S68-576.

70. Covanis A. Epileptic encephalopathies (including severe epilepsy syndromes). Epilepsia. 2012;53(Suppl 4):114-26. https://doi.org/10.1111/ j.1528-1167.2012.03621.x.

71. Coppola G, Plouin P, Chiron C, Robain O. Migrating partial seizures in infancy: a malignant disorder with developmental arrest. Epilepsia. 1995;36:1017-24.

72. Coppola G. Malignant migrating partial seizures in infancy. Handb Clin Neurol. 2013;111:605-9.

73. McTaque A, Appleton R, Avula S, Cross JH, King MD, Jacques TS, Bhate S, Cronin A, Curran A, Desurkar A, Farrell MA. Migrating partial seizures of infancy: expansion of the electroclinical, radiological and pathological disease spectrum. Brain. 2013;136(Pt 5):1578-91.

74. Howell KB, MCMahon JM, Carvill GL, et al. SCN2A encephalopathy: a major cause of epilepsy of infancy with migrating focal seizures. Neurology. 2015;85:958-66.

75. Lux AL, Osborne JP. A proposal for case definitions and outcome measures in studies of infantile spasms and west syndrome: consensus statement of the west Delphi group. Epilepsia. 2004;45:1416-28.

76. Scheffer IE, Berkovic S, Capovilla G, Connolly MB, French J, Guilhoto L, Hirsch E, Jain S, Mathem GW, Mosche SL, Perucca E, Tomson T, Wiebe S, Zhang YH, Zuberi SM. ILAE classification of the epilepsies: position paper of the ILAE Commission for Classification and Terminology. Epilepsia. 2017;58:512-21.

77. Lux AL. Latest American and European updates on infantile spasms. Curr Neurol Neurosci Rep. 2013;13:334. https://doi.org/10.1007/s11910-012-0334-z.

78. Riikonen R, Donner M. Incidence and aetiology of infantile spasms from 1960 to 1976: a population study in Finland. Dev Med Child Neurol. 1979;21:333-43

79. Wallerstein R, Sugalski R, Cohn L. Expansion of the ARX spectrum. Clin Neurol Neurosurg. 2008;110:631-4.

80. Paciorkowski AR, Thio LL, Dobyns WB. Genetic and biologic classification of infantile spasms. Pediatr Neurol. 2011;45:355-67.

81. Guerrini R, Filippi T. Neuronal migration disorders, genetics, and epileptogenesis. J Child Neurol. 2005;20:287-99.

82. Masliah-Plachon J, Auvin S, Nectoux J, Fichou Y, Chelly J, Bienvenu F. Somatic mosaicism for a CDKL5 mutation as an epileptic encephalopathy in males. Am J Med Genet A. 2010;152A:2110-1.

83. Deprez L, Weckhuysen S, Holmgren P, Suls A, Van Dyck T. Clinical spectrum of early-onset epileptic encephalopathies associated with STXBP1 mutations. Neurology. 2010;75:1159-65.

84. Kossoff EH, Rowley H, Sinha SR. A prospective study of the modified Atkins diet for intractable epilepsy in adults. Epilepsia. 2008;49:316-9.

85. Mudigoudar B, Weatherspoon S, et al. Emerging antiepileptic drugs for severe pediatric epilepsies. Semin Pediatr Neurol. 2016;23:167-79.

86. Dravet C. Les épilepsies graves de l'enfant. Vie Med. 1978;8:543-8.

87. Dravet C, Bureau M, Oguni H, Fukuyama Y, Cokar O. Severe myoclonic epilepsy in infancy: Dravet syndrome. Adv Neurol. 2005;95:71-102. 
88. Dravet C. The core Dravet syndrome phenotype. Epilepsia. 2011;52(Suppl 2):3.

89. Hurst DL. Epidemiology of severe myoclonic epilepsy of infancy. Epilepsia. 1990;31:397-400

90. Wu YW, Sullivan J, McDaniel SS, Meisler MH, Walsh EM, Li SX, Kuzniewicz MW. Incidence of Dravet syndrome in a US population. Pediatrics. 2015;136:e1310-5.

91. Scheffer IE, Zhang YH, Jansen FE, Dibbens L. Dravet syndrome or genetic (generalized) epilepsy with febrile seizures plus? Brain and Development 2009;31:394-400.

92. Kim YO, Bellows S, McMahon JM, Iona X, Damiano J, Dibbens L. Atypical multifocal Dravet syndrome lacks generalized seizures and may show later cognitive decline. Dev Med Child Neurol. 2014;56:85-90.

93. Zucca C, Redaelli F, Epifanio R, Zanotta N, Romeo A, Lodi M, Veggiotti P, Airoldi G, Panzeri C. Cryptogenic epileptic syndromes related to SCN1A: twelve novel mutations identified. Arch Neurol. 2008;65:489-94.

94. Praticò AD, Falsaperla R, Ruggieri M, Corsello G, Pavone P. Prognostic challenges of SCN1A genetic mutations: report on two children with mild features. J Pediatr Neurol. 2016;14:82-8.

95. Villas N, Meskis MA, Goodliffe S. Dravet syndrome: characteristics, comorbidities, and caregiver concerns. Epilepsy Behav. 2017;74:81-6.

96. Marini C, Scheffer IE, Nabbout R, Suls A. The genetics of Dravet syndrome. Epilepsia. 2011;52(Suppl 2):24-9.

97. Connolly MB. Dravet syndrome: diagnosis and long-term course. Can J Neurol Sci. 2016;43(Suppl 3):S3-58.

98. Gataullina S, Dulac O. From genotype to phenotype in Dravet disease. Seizure. 2017:44:58-64.

99. Brunklaus A, Dorris L, Ellis R, Reavey E, Lee E, Forbes $G$. The clinical utility of an SCN1A genetic diagnosis in infantile-onset epilepsy. Dev Med Child Neurol. 2013;55:154-61.

100. Zuberi SM, Brunklaus A, Birch R, Reavey E, Duncan J, Forbes GH. Genotype- phenotype associations in SCN1A-related epilepsies. Neurology. 2011;76:594-600.

101. Escayg A, Heils A, MacDonald BT. A novel SCN1A mutation associated with generalized epilepsy with febrile seizures plus-and prevalence of variants in patients with epilepsy. Am J Hum Genet. 2001;68:866-73.

102. Wallace RH, Scheffer IE, Barnett S, Richards M, Dibbens L, Desai RR. Neuronal sodium-channel alpha1-subunit mutations in generalized epilepsy with febrile seizures plus. Am J Hum Genet. 2001:68:859-65.

103. Shmuely S, Sisodiya SM, Gunning WB. Mortality in Dravet syndrome: a review. Epilepsy Behav. 2016;64(Pt A):69-74.

104. Cho MJ, Kwon SS, Ko A, Lee ST, Lee YM, Kim HD, Chung HJ, Kim SH, Lee JS, Kim DS, Kang HC. Efficacy of Stiripentol in Dravet syndrome with or without SCN1A mutations. J Clin Neurol. 2017:31:1-6.

105. Morimoto M, Shimakawa S, Hashimoto T, Kitaoka T, Kyotani S. Marked efficacy of combined three-drug therapy (sodium valproate, Topiramate and Stiripentol) in a patient with Dravet syndrome. J Clin Pharm Ther. 2017; https://doi.org/10.1111/jcpt.12659.

106. Myers KA, Lighfoot P, Patil SG, Cross JH, Scheffer IE. Stiripentol efficacy and safety in Dravet syndrome: a 12-year observational study. Dev Med Chikd Neurol. 2018; https://doi.org/10.1111/dmcn.13704.

107. Wirrell EC, Laux L, Franz DN, Sullivan J, Saneto RP, Morse RP, Devinsky O, Chugani H, Hernandez A, Hamiwka L, Mikati MA. Stiripentol in Dravet syndrome: results of a retrospective U.S. study. Epilepsia. 2013 Sep;54(9):1595-604. https://doi.org/10.1111/epi.12303.

108. De Liso P, Vigevano F, Specchio N, De Palma L. Effectiveness and tolerability of perampanel in children and adolescents with refractory epilepsies-an Italian observational multicenter study. Epilepsy Res. 2016;127:93-100.

109. Dalla Bernardina B, Trevisan C, Bondavelli S. Une forme particuliere d'epilepsie mjoclonique chez des enfants d'encephalopathy fixee. Boll Lega It Epil. 1980;29-30:183-7.

110. Elia M. Myoclonic status in nonprogressive encephalopathies: an update. Epilepsia. 2009:50(Suppl 5):41-4. https://doi.org/10.1111/j.1528-1167.2009.02119x

111. Caraballo R, Cersósimo R, Espeche A, Arrovo HA, Fejerman N. Myoclonic status in nonprogressive encephalopathies. Epilepsia. 2007:48:1054-61.

Ready to submit your research? Choose BMC and benefit from:

- fast, convenient online submission

- thorough peer review by experienced researchers in your field

- rapid publication on acceptance

- support for research data, including large and complex data types

- gold Open Access which fosters wider collaboration and increased citations

- maximum visibility for your research: over $100 \mathrm{M}$ website views per year

At BMC, research is always in progress.

Learn more biomedcentral.com/submissions 